\title{
Austerity and the rise of food banks
}

\author{
Trevor Jackson deputy editor, The BMJ
}

In the first of the four pre-election television debates, interviewer Jeremy Paxman asked the UK prime minister, David Cameron, "How many food banks were there in this country when you came to power?" Looking slightly flummoxed, Cameron replied, "I don't know the exact figures, but I know use of food banks has gone up." Paxman pointed out that since 2010 the number of food banks had risen from 66 to 421, while around 900000 people had received free food parcels last year. Paxman then challenged the prime minister to say whether or not it was "acceptable in a rich country like ours that there are that number of people dependent on free food aid." Cameron responded, "I want fewer people to be using food banks."

The implication that hung heavy in Paxman's challenge was that there might be a link between the current government's austerity policies and "food insecurity." In The BMJ this week Rachel Loopstra and colleagues say this can be defined as "the state of being without reliable access to a sufficient quantity of affordable nutritious food" (doi:10.1136/bmj.h1775). In their Analysis article they examine the crucial question of supply and demand that often gets asked in discussions about the rise of food banks in a country with the world's sixth largest economy: to what extent are food banks a response to genuine need and to what extent do they create it? To test the two competing hypotheses Loopstra and colleagues linked data about food bank use to budgetary and socioeconomic data from 375 UK local authorities from 2006-07 to 2013-14. Did the authorities in which food banks opened between 2010 and 2013 have greater economic hardship as represented by unemployment rates, austerity measures (including central and local government welfare cuts), or rates of benefit sanctioning than those in which food banks did not open?
The authors' conclusion is that, yes, more food banks open in areas that bear the brunt of welfare cuts and where more people experience benefit sanctions. They also show that food parcel distribution is higher in areas where food banks are more common and better established, "but our data also show that the local authorities with greater rates of sanctions and austerity are experiencing greater rates of people seeking emergency food assistance." But Loopstra and colleagues add that it is likely that they underestimated use of food banks in the UK, because of difficulties with the data, because they studied only one (albeit the largest) provider of food banks, the Trussell Trust, and because food bank use is not consistently monitored in the UK, as it is in some other countries.

Doctors, along with social workers, health visitors, and police officers, are having to take on a role as gatekeepers to food banks. The Analysis authors cite a recent survey of 522 general practitioners that found that $16 \%$ had been asked for such referrals. The Trussell Trust estimates that 27000 frontline professionals provided referrals in 2013-14. Loopstra and colleagues say that, rather than accept this situation, "an alternative is to call for action on the root social and economic factors that trigger reliance on food banks."

Doctors, along with social workers, health visitors, and police officers, are having to take on a role as gatekeepers to food banks

For more from The BMJ on the UK general election go to bmj.co/election.

Cite this as: BMJ 2015;350:h1880

(๑) BMJ Publishing Group Ltd 2015 